\title{
High-Cycle Fatigue Behavior of Austenitic Steel and Pure Copper under Uniaxial, Proportional and Non-Proportional Loading
}

\author{
Łukasz Pejkowski* - Dariusz Skibicki - Janusz Sempruch \\ University of Technology and Life Sciences in Bydgoszcz, Poland
}

Austenitic steel EN: X2CrNiMo17-12-2 (ASTM: 316L) and copper Cu-ETP (DIN: E-Cu58, EN: CW004A, ASTM: C11000) were subjected to tension-compression, torsion and complex loads, including non-proportional loads. The non-proportionality of the state of stress resulted from a phase shift of the value $\delta=90^{\circ}$ of load components with sine signals and variable ratio of shear to normal stress $\lambda$.

On the basis of the results, Wöhler's curves were prepared, presenting the dependency of fatigue life to equivalent stress levels. Their analysis shows that fatigue life is strictly connected with the value of coefficient $\lambda$. The existence of its critical value can also be observed, which results in the highest fatigue life reduction. The value is different for each material. Furthermore, fractographic tests were conducted showing the influence of the level and type of load on the fracture face.

Keywords: multi-axial fatigue, high cycle fatigue, non-proportional load, fractography, out-of-phase

\section{O INTRODUCTION}

The negative impact of the non-proportionality of stress components on fatigue strength and fatigue life [1] and [2] was observed in relation to a significant number of materials. Its direct effect is the phenomenon of additional hardening [3] to [5]. Nonproportionality can result from periodic load signals with phase shift (Fig. 1a) [6] to [8], asynchronous periodic signals (Fig. 1b) and random signals (Fig. 1c) [9] to [11] among other factors

In cases of periodic out-of-phase signals of components of stress, the most damaging to the material, regardless of its type, is phase shift, expressed by the value of angle $\delta=90^{\circ}$. The degree of non-proportionality of stress condition also depends on the ratio of amplitudes of shear to normal stress $\lambda=\tau_{a} / \sigma_{a}$, which is usually omitted in works that analyse non-proportional loads.

The objective of the this study is to analyse the influence of the $\lambda$ ratio on fatigue life and the fatigue fracture surface morphology and crack plane orientation (which often are the subject of interest [9], [12] and [13]) for copper Cu-ETP and austenitic steel $\mathrm{X} 2 \mathrm{CrNiMo17-12-2}$. The materials were selected for tests due to their potentially high sensitivity to nonproportionality of load [14].

\section{TESTS CONDITIONS}

All fatigue tests were conducted with application of a fully reversed sine signal $(R=-1)$ of constant amplitude, with stress control, using an Instron 8874 biaxial testing system with a load range of $\pm 25 \mathrm{kN}$ for tension-compression and $\pm 100 \mathrm{Nm}$ for torsion (Fig. 2).

Specimens were made by the machining of material as delivered. Specimen dimensions are presented on Fig. 3. Chemical composition of the tested steel and copper type are presented in Tables 1 and 2.

The specimens were subject to tensioncompression, torsion, proportional load $(\lambda=0.5)$ and non-proportional loads $\left(0.3<\lambda<0.8, \delta=90^{\circ}\right)$.
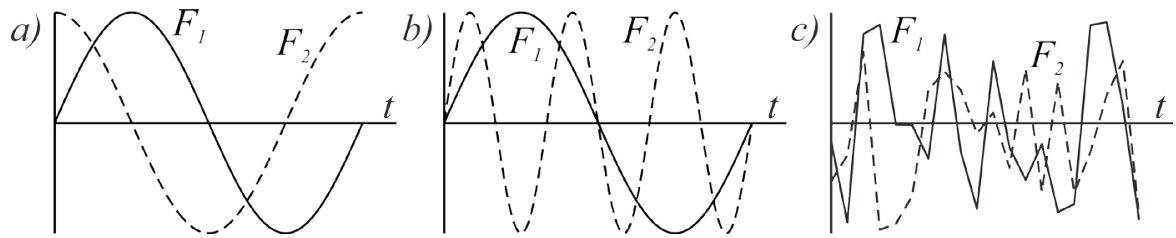

Fig. 1. Examples of loads signals causing non-proportional condition of stress; a) out-of-phase load signals b) asynchronous load signals, and c) random load signals

Table 1. Chemical composition of X2CrNiMo17-12-2 steel (\% weight)

\begin{tabular}{cccccccccc}
\hline $\mathrm{C}$ & $\mathrm{Si}$ & $\mathrm{Mn}$ & $\mathrm{Ni}$ & $\mathrm{P}$ & $\mathrm{S}$ & $\mathrm{Cr}$ & $\mathrm{M} 0$ & $\mathrm{~N}$ & \\
\hline$<0.03$ & $<1$ & $<2$ & 10 to 13 & $<0.045$ & $<0.015$ & 16.5 to 18.5 & 2 to 2.5 & $<0.11$ \\
\hline
\end{tabular}


Table 2. Chemical composition of Cu-ETP copper (\% weight)

\begin{tabular}{cccc}
\hline $\mathrm{Cu}$ & $\mathrm{Bi}$ & 0 & $\mathrm{~Pb}$ \\
\hline$>99.9$ & $<0.0005$ & $<0.04$ & $<0.005$ \\
\hline
\end{tabular}

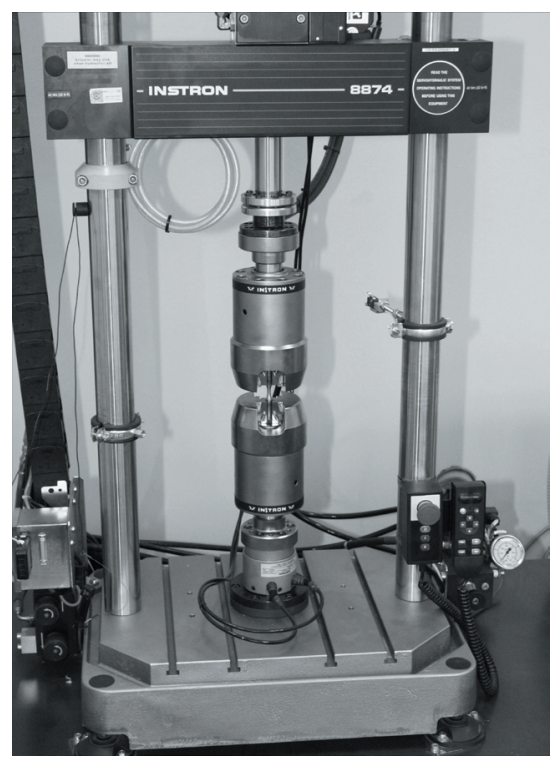

Fig. 2. Instron 8874 biaxial testing system

Values of amplitudes were selected in order to obtain the exact value of amplitude (denoted as in subscript) of root mean square of the second invariant of stress deviator, $\sqrt{J_{2, a}}$ [15], multiplied by fatigue limits ratio for a given load level. The value can be written as follows:

$$
\sigma_{e q}=\frac{\tau_{-1}}{\sigma_{-1}} \sqrt{J_{2, a}}=\text { const. }
$$

The above value is the equivalent stress according to von Mises criterion:

$$
\sigma_{e q}=\sqrt{3} \sqrt{J_{2, a}}
$$

with consideration of fatigue limits ratio for torsion and tension-compression $\tau_{-1} / \sigma_{-1}$, in place of the constant value $\sqrt{3}$. The von Mises criterion does not take into account the non-proportionality of load. The choice of such a criterion has been made deliberately, in order to show how the variable degree of nonproportionality, depending on the value of $\lambda$ ratio, affects the fatigue life.

$\mathrm{TC}$ indicates the results for tension-compression, $\mathrm{T}$ is torsion, P5 proportional load of coefficient $\lambda=0.5$ and non-proportional loads, expressed as $N P$, of values of coefficient $\lambda=0.3,0.4,0.5,0.53,0.6,0.7$, 0.8 , respectively.

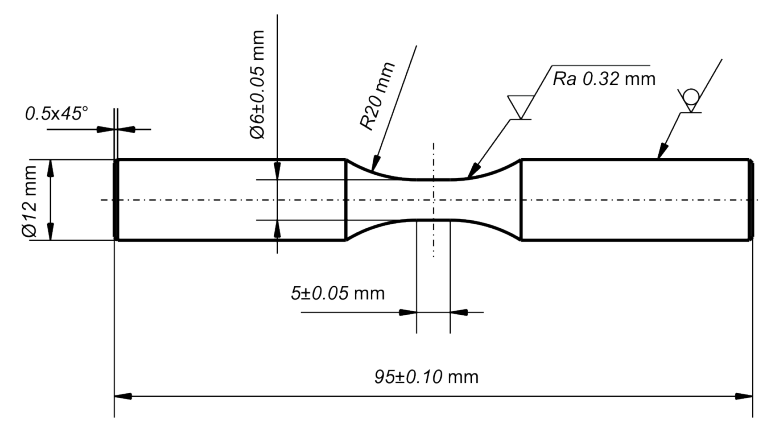

Fig. 3. Geometry of tested specimens

Fig. 4 shows state of stress on the surface of the specimen and distribution of normal stress $\sigma_{\alpha}$, shear stress $\tau_{\alpha}$ and von Mises equivalent stress $\sigma_{M \alpha}$ acting on specimen surface, depending on the direction expressed by $\alpha$ angle.

\section{TEST RESULTS}

\subsection{Fatigue Life}

A summary of the test results is presented in Tables 3 and 4 .

Fig. 5 presents Wöhler's curves obtained for copper $\mathrm{Cu}$-ETP. On the ordinate axis, the values of equivalent stress $\sigma_{e q}$ (according to von Mises criterion) and on abscissa axis lives expressed with number of cycles $N$ were identified. The curves were described with the Basquin equation:

$$
\sigma_{e q}=A N^{B}
$$

coefficient $A$ and exponent $B$ of which were obtained via least square linear regression. The procedure of generating a line of best fit is well known in fatigue literature and its description can be found in [16] as well as in other sources. The resulting coefficients of determination $R 2$ are denoted in Figs. 5 and 8. After transformation of the Basquin equation:

$$
N=\left(\frac{\sigma_{e q}}{A}\right)^{\frac{1}{B}},
$$

it is possible to calculate the fatigue life as the material is supposed to reach for the specific value of equivalent stress. The values of equivalent stresses calculated for various loads were placed into a transformed Basquin's equation coefficients, which were determined for tension-compression; in this way the calculated fatigue lives $N_{c a l}$ were specified. Then they were compared with experimental fatigue lives 

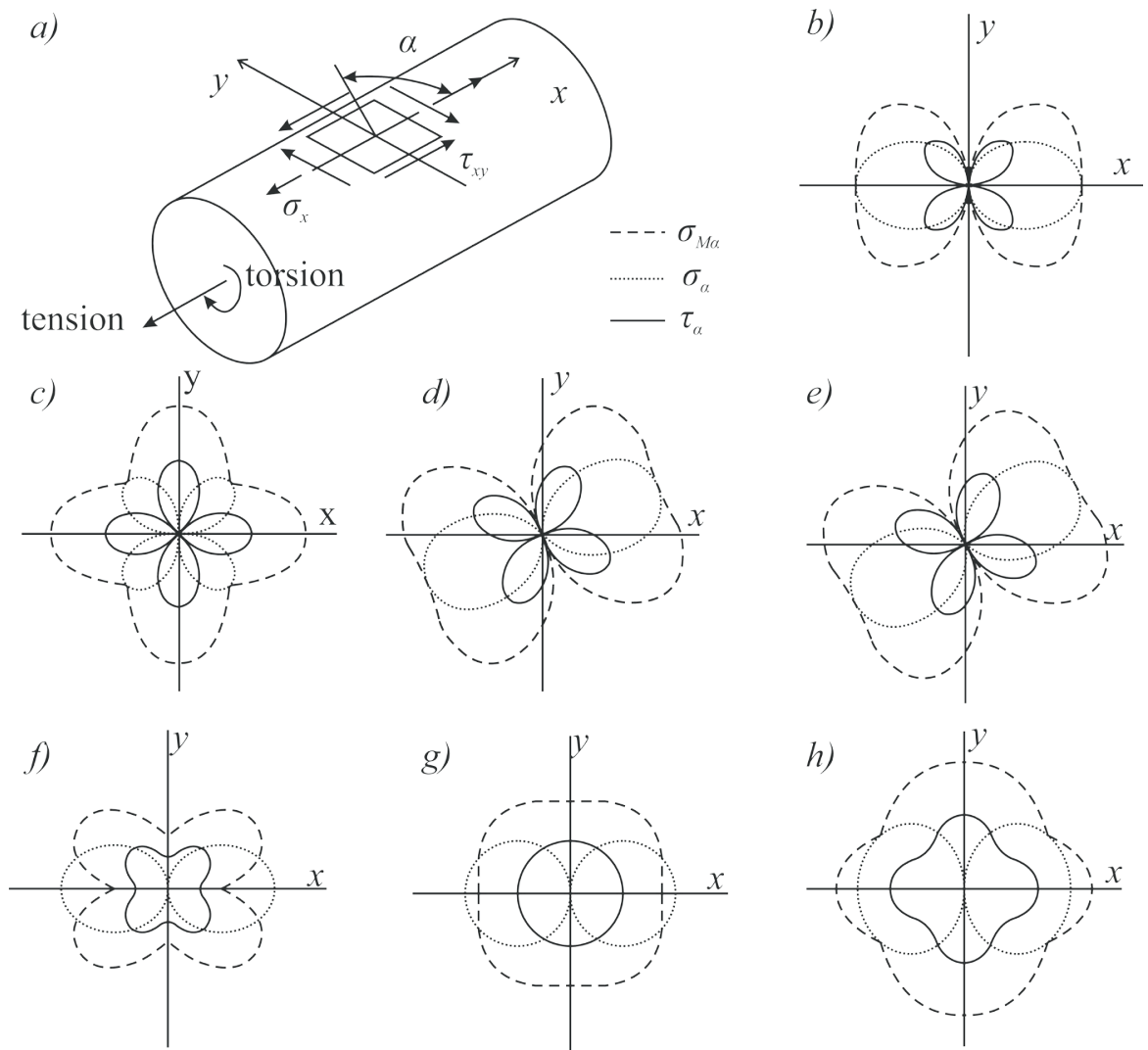

Fig. 4. a) Out-of-phase tension-compression and torsion - state of stress illustrated b) distribution of Von Mises equivalent stress $\sigma_{M \alpha}$, normal stress $\sigma \alpha$ and shear stress $T \alpha$ on a plane tangent to specimen surface in case of tension-compression, $c)$ torsion, $d$ ) proportional tensioncompression with torsion $\lambda=0.5$, e) proportional tension-compression with torsion $\lambda=0.8, f$ ) non-proportional tension-compression with torsion $\lambda=0.3$, g) non-proportional tension-compression with torsion $\lambda=0.5$, and $h$ ) non-proportional tension-compression with torsion $\lambda=0$

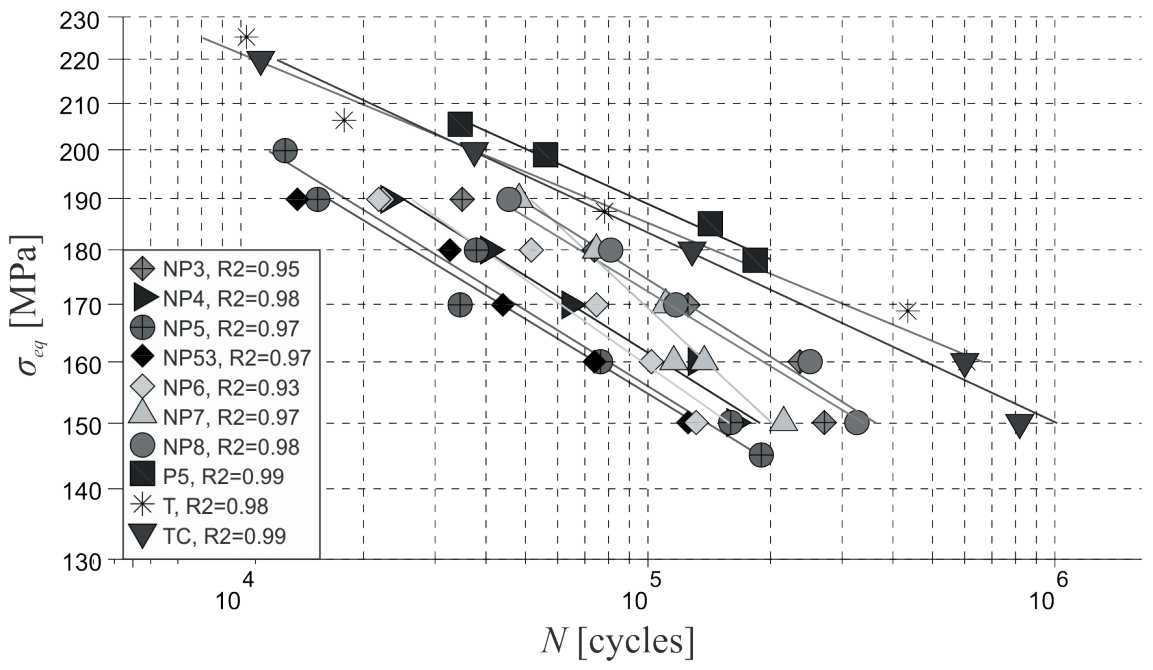

Fig. 5. Wöhler's curves obtained for CU-ETP copper for various load types

$N_{\text {exp }}$ achieved for tension-compression. Comparative results are presented in Fig. 6. Solid and dotted lines on the figure symbolize scatter bands, which indicate lives that are two and three times longer or shorter than experimental ones.
Fig. 7 presents a graph of dependency of fatigue life on $\lambda$ at the level of equivalent stresses $\sigma_{e q}=160 \mathrm{MPa}$.

Analogously, the following were prepared: Wöhler's curves (Fig. 8), a fatigue life comparison 
Table 3. Test history for all fatigue specimens for Cu-ETP copper

\begin{tabular}{|c|c|c|c|c|c|}
\hline $\begin{array}{c}\text { Specimen } \\
\text { no. }\end{array}$ & $\begin{array}{l}\text { Load } \\
\text { type }\end{array}$ & $\begin{array}{c}\sigma_{a} \\
{[\mathrm{MPa}]}\end{array}$ & $\begin{array}{c}\tau_{a} \\
{[\mathrm{MPa}]}\end{array}$ & $\begin{array}{c}\delta \\
{\left[{ }^{\circ}\right]}\end{array}$ & $\begin{array}{c}N \\
\text { [no. of cycles] }\end{array}$ \\
\hline 2 & TC & 220 & 0 & 0 & 11,247 \\
\hline 3 & TC & 200 & 0 & 0 & 37,432 \\
\hline 4 & TC & 180 & 0 & 0 & 128,933 \\
\hline 5 & $\mathrm{TC}$ & 150 & 0 & 0 & 816,270 \\
\hline 73 & TC & 160 & 0 & 0 & 601,749 \\
\hline 8 & $T$ & 0 & 90 & 0 & 432,462 \\
\hline 9 & $\mathrm{~T}$ & 0 & 110 & 0 & 17,893 \\
\hline 10 & $\mathrm{~T}$ & 0 & 100 & 0 & 78,004 \\
\hline 11 & $T$ & 0 & 120 & 0 & 10,269 \\
\hline 74 & $T$ & 0 & 85.4 & 0 & 607,029 \\
\hline 12 & P5 & 130 & 65 & 0 & 184,190 \\
\hline 13 & P5 & 150 & 75 & 0 & 34,694 \\
\hline 14 & P5 & 135 & 67 & 0 & 142,212 \\
\hline 15 & P5 & 145 & 72 & 0 & 55,991 \\
\hline 30 & N3 & 170 & 51 & 90 & 125,877 \\
\hline 22 & N3 & 180 & 54 & 90 & 74,163 \\
\hline 29 & N3 & 190 & 57 & 90 & 35,145 \\
\hline 55 & N3 & 160 & 48 & 90 & 235,151 \\
\hline 69 & N3 & 150 & 45 & 90 & 272,506 \\
\hline 46 & N4 & 170 & 68 & 90 & 64,318 \\
\hline 47 & N4 & 180 & 72 & 90 & 40,812 \\
\hline 48 & N4 & 190 & 76 & 90 & 23,197 \\
\hline 56 & N4 & 160 & 64 & 90 & 130,741 \\
\hline 70 & N4 & 150 & 60 & 90 & 164,044 \\
\hline 16 & N5 & 145 & 72 & 90 & 189,644 \\
\hline 17 & N5 & 160 & 80 & 90 & 76,203 \\
\hline 18 & N5 & 180 & 90 & 90 & 37,971 \\
\hline 19 & N5 & 200 & 100 & 90 & 12,829 \\
\hline 50 & N5 & 170 & 85 & 90 & 34,726 \\
\hline 51 & N5 & 190 & 95 & 90 & 15,371 \\
\hline 68 & N5 & 150 & 75 & 90 & 159,779 \\
\hline 52 & N53 & 180 & 96 & 90 & 32,710 \\
\hline 53 & N53 & 170 & 90.7 & 90 & 44,034 \\
\hline 54 & N53 & 190 & 101.3 & 90 & 13,770 \\
\hline 58 & N53 & 160 & 85.3 & 90 & 73,917 \\
\hline 67 & N53 & 150 & 80 & 90 & 125,195 \\
\hline 37 & N6 & 151.1 & 90.7 & 90 & 74,900 \\
\hline 35 & N6 & 160 & 96 & 90 & 51,551 \\
\hline 45 & N6 & 169 & $\begin{array}{l}101.4 \\
\end{array}$ & 90 & 22,322 \\
\hline 49 & N6 & 169 & 101.4 & 90 & 21,833 \\
\hline 57 & N6 & 142.2 & 85.3 & 90 & 101,644 \\
\hline 71 & N6 & 133.4 & 80 & 90 & 130,712 \\
\hline 23 & N7 & 137.1 & 96.0 & 90 & 74,395 \\
\hline 31 & N7 & 144.8 & 101.4 & 90 & 48,146 \\
\hline 43 & N7 & 129.6 & 90.7 & 90 & 110,808 \\
\hline 59 & N7 & 121.9 & 85.3 & 90 & 115,927 \\
\hline 65 & N7 & 121.9 & 85.3 & 90 & 137,314 \\
\hline 72 & N7 & 114.3 & 80 & 90 & 215,815 \\
\hline 28 & N8 & 113.4 & 90.7 & 90 & 117,308 \\
\hline 20 & N8 & 120 & 96.0 & 90 & 80,724 \\
\hline 27 & N8 & 126.7 & 101.4 & 90 & 45,681 \\
\hline 60 & N8 & 106.7 & 85.4 & 90 & 249,457 \\
\hline 66 & N8 & 100 & 80 & 90 & 326,218 \\
\hline
\end{tabular}

graph (Fig. 9), and a graph of fatigue life dependency on $\lambda$ (Fig. 10), for $\mathrm{X} 2 \mathrm{CrNiMo17-12-2}$ steel for tension-compression $(T C)$, torsion $(T)$, proportional load $(P)$ of $\lambda$ value 0.5 and 0.8 and non-proportional $(N P)$ with $\lambda=0.5,0.8$ and 1.0 .

In case of both tested materials, the fatigue lives of specimens subject to uniaxial load and proportional
Table 4. Test history for all fatigue spec. for X2CrNiMo17-12-2 steel

\begin{tabular}{|c|c|c|c|c|c|}
\hline $\begin{array}{c}\text { Specimen } \\
\text { no. }\end{array}$ & $\begin{array}{l}\text { Load } \\
\text { type }\end{array}$ & $\begin{array}{c}\sigma_{a} \\
{[\mathrm{MPa}]}\end{array}$ & $\begin{array}{c}\tau_{a} \\
{[\mathrm{MPa}]}\end{array}$ & $\begin{array}{c}\delta \\
{\left[{ }^{\circ}\right]}\end{array}$ & $\begin{array}{c}N \\
\text { [no. of cycles] }\end{array}$ \\
\hline 1 & TC & 350 & 0 & 0 & 23,420 \\
\hline 2 & TC & 350 & 0 & 0 & 14,937 \\
\hline 3 & TC & 350 & 0 & 0 & 18,048 \\
\hline 4 & TC & 330 & 0 & 0 & 75,013 \\
\hline 5 & TC & 330 & 0 & 0 & 49,513 \\
\hline 6 & TC & 330 & 0 & 0 & 68,038 \\
\hline 7 & TC & 342 & 0 & 0 & 25,225 \\
\hline 11 & TC & 325 & 0 & 0 & 139,108 \\
\hline 8 & TC & 325 & 0 & 0 & 89,469 \\
\hline 10 & TC & 311 & 0 & 0 & 199,142 \\
\hline 9 & TC & 303 & 0 & 0 & 632510 \\
\hline 15 & TC & 325 & 0 & 0 & 146,934 \\
\hline 16 & TC & 311 & 0 & 0 & 147,769 \\
\hline 21 & TC & 325 & 0 & 0 & 190,912 \\
\hline 22 & TC & 325 & 0 & 0 & 112,227 \\
\hline 23 & TC & 303 & 0 & 0 & 235,423 \\
\hline 24 & TC & 311 & 0 & 0 & 174,567 \\
\hline 72 & TC & 333.3 & 0 & 0 & 39,467 \\
\hline 33 & $\mathrm{~T}$ & 0 & 310 & 0 & 9,108 \\
\hline 34 & $T$ & 0 & 300 & 0 & 10,197 \\
\hline 35 & $T$ & 0 & 290 & 0 & 11,202 \\
\hline 36 & $T$ & 0 & 260 & 0 & 135,216 \\
\hline 37 & $\mathrm{~T}$ & 0 & 250 & 0 & 599,432 \\
\hline 38 & $\mathrm{~T}$ & 0 & 270 & 0 & 106,582 \\
\hline 39 & $\mathrm{~T}$ & 0 & 280 & 0 & 58,678 \\
\hline 73 & $T$ & 0 & 276 & 0 & 30,801 \\
\hline 40 & $\mathrm{P} 5$ & 270 & 135 & 0 & 167,175 \\
\hline 41 & $\mathrm{P} 5$ & 285 & 142.5 & 0 & 81,692 \\
\hline 46 & $\mathrm{P} 5$ & 299 & 149.8 & 0 & 14,444 \\
\hline 71 & P5 & 285 & 142.5 & 0 & 98,892 \\
\hline 47 & P8 & 247 & 204.6 & 0 & 35,318 \\
\hline 48 & P8 & 233 & 193.1 & 0 & 61,307 \\
\hline 49 & P8 & 219 & 181.4 & 0 & 215,220 \\
\hline 42 & N5 & 333 & 166.5 & 90 & 24,697 \\
\hline 45 & N5 & 320 & 160 & 90 & 45,993 \\
\hline 54 & N5 & 310 & 155 & 90 & 106,276 \\
\hline 53 & N5 & 300 & 150 & 90 & 127,454 \\
\hline 61 & N5 & 333 & 166.5 & 90 & 23,027 \\
\hline 62 & N5 & 320 & 160 & 90 & 62,307 \\
\hline 63 & N5 & 310 & 155 & 90 & 158,758 \\
\hline 64 & N5 & 300 & 150 & 90 & 368,041 \\
\hline 70 & N5 & 333 & 166.5 & 90 & 26,124 \\
\hline 108 & N6 & 310 & 186 & 90 & 35,742 \\
\hline 112 & N6 & 333 & 199,8 & 90 & 20,109 \\
\hline 13 & N6 & 320 & 192 & 90 & 27,697 \\
\hline 114 & N6 & 300 & 180 & 90 & 86,619 \\
\hline 43 & N8 & 333 & 275.1 & 90 & 12,810 \\
\hline 44 & N8 & 320 & 264.3 & 90 & 28,491 \\
\hline 50 & N8 & 310 & 256.1 & 90 & 28,341 \\
\hline 51 & N8 & 300 & 247.8 & 90 & 34,506 \\
\hline 55 & N8 & 333 & 275.1 & 90 & 10,264 \\
\hline 56 & N8 & 320 & 264.3 & 90 & 10,856 \\
\hline 57 & N8 & 310 & 256.1 & 90 & 29,734 \\
\hline 58 & N8 & 300 & 247.8 & 90 & 11,663 \\
\hline 59 & N8 & 320 & 264.3 & 90 & 23,124 \\
\hline 60 & N8 & 300 & 247.8 & 90 & 40,540 \\
\hline 96 & $\mathrm{~N} 10$ & 260 & 260.0 & 90 & 30,219 \\
\hline 105 & N10 & 244 & 240 & 90 & 120,406 \\
\hline 106 & N10 & 251,8 & 251,8 & 90 & 46,128 \\
\hline 107 & N10 & 270,5 & 270,5 & 90 & 14,952 \\
\hline 115 & $\mathrm{~N} 12$ & 203,1 & 243,7 & 90 & 67,318 \\
\hline 116 & $\mathrm{~N} 12$ & 209,9 & 251,9 & 90 & 63,312 \\
\hline 117 & $\mathrm{~N} 12$ & 216,6 & 259,9 & 90 & 40,951 \\
\hline 118 & N12 & 225,5 & 270,6 & 90 & 14,395 \\
\hline
\end{tabular}




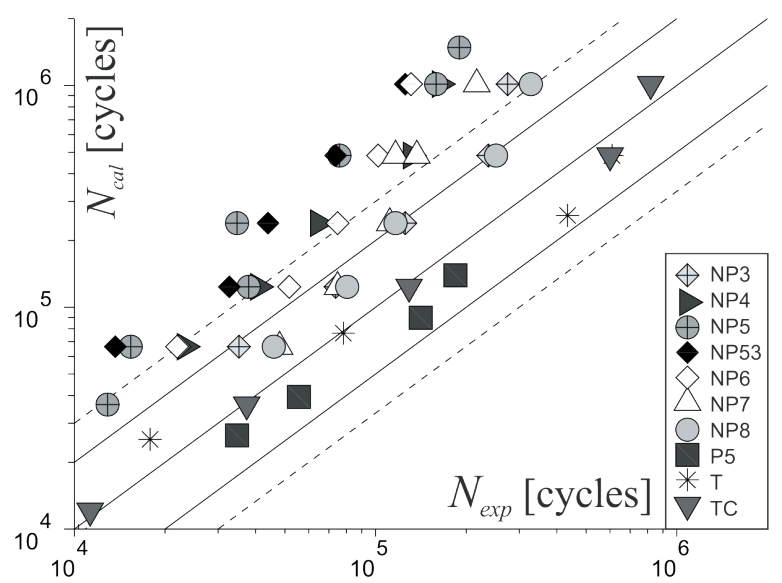

Fig. 6. Comparison of experimental fatigue lives for tensioncompression with calculated fatigue lives for CU-ETP copper

load, yielding the same value of equivalent stress $\sigma_{e q}$, are very close. At the same time, the fatigue life of specimens subject to non-proportional loads is lower. Fatigue life reduction significantly depends on $\lambda$. Its highest reduction in the case of copper can be observed for $\lambda=0.53 \approx \tau_{-1} / \sigma_{-1}$, and for steel for $\lambda=0.8 \approx \tau_{-1} / \sigma_{-1}$.

\subsection{Macrofractography}

Fig. 11 presents, on the background of Wöhler's curves, the images of fracture surfaces morphology and cracks of $\mathrm{Cu}$-ETP specimens subject to tensioncompression $(T C)$. In all fracture surfaces, the tensilemechanism, indicating mode and fracture load can

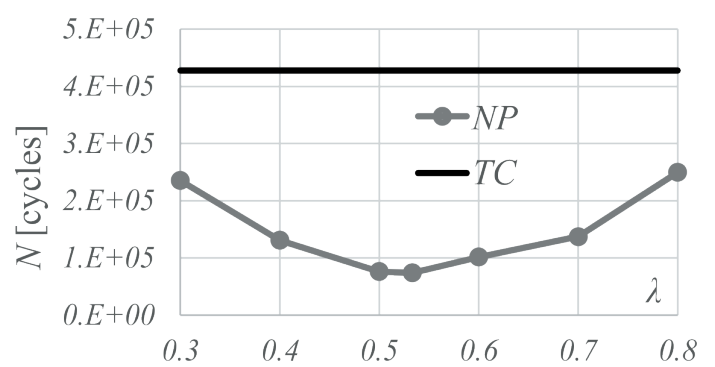

Fig. 7. Dependency of fatigue life on $\lambda$ for CU- ETP, at the level of $\sigma_{e q}=160 \mathrm{MPa}$

be observed. Fracture is perpendicular to the load direction. There was Case A and B crack growth (Case A grew along the surface of a material; Case B grew into the depth of a material [3]). At higher load levels, there are ratchet marks visible, indicating the initiation of cracking with multiple origins and a relatively big fast fracture zone.

In Fig. 12, images of surface fracture morphology and $\mathrm{Cu}$-ETP cracks from specimens being subjected to torsion are shown. Cracks were loaded in mode II, meaning that the shear mechanism operated. In all specimens, the direction of macro-crack is compliant with the direction of maximum shear stress.

Fig. 13 shows images of surface fracture morphology and Cu-ETP cracks from specimens being subjected to a proportional load of coefficient $\lambda=0.5$. The fracture face of the most loaded specimen resembles the fracture face of a specimen subject to tension-compression of low stress value. There are no ratchet marks and many origins, and the fracture

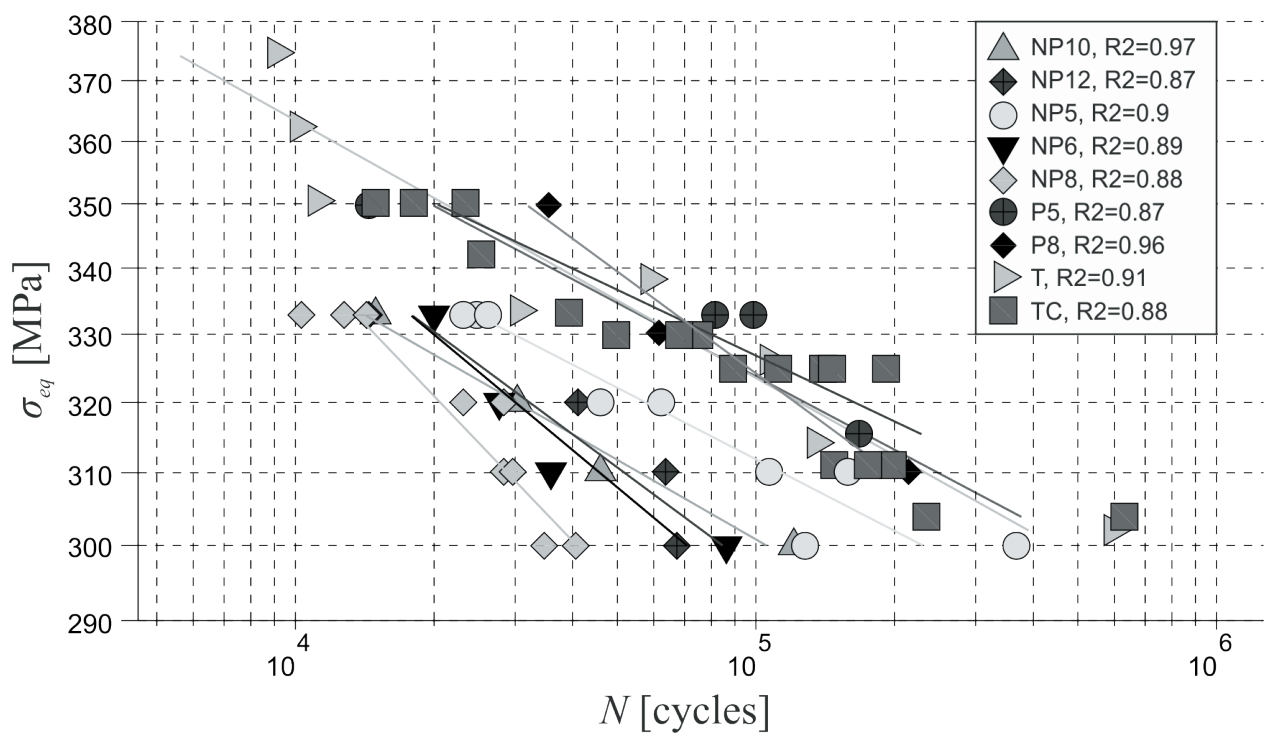

Fig. 8. Wöhler's curves obtained for X2CrNiMo17-12-2 steel for various load types 
zone is relatively small. One can observe more crack growth in Case A than in a case of pure shear. The higher the load level, the greater the number of origins and ratchet marks, being inclined and tapered, indicating the participation of torsion.

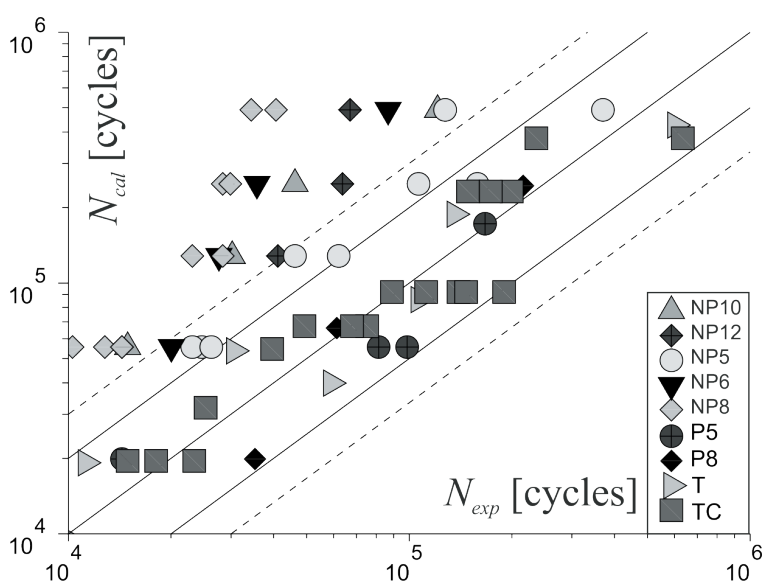

Fig. 9. Comparison of experimental fatigue lives for tensioncompression with calculated fatigue lives for X2CrNiMo17-12-2 steel

Images of surface fracture morphology and cracks in $\mathrm{Cu}$-ETP specimens for non-proportional loads of three various values of coefficient $\lambda$ are presented in Fig. 14. In the case of $\lambda=0.3$, surface fractures of the most highly loaded specimen, is as for the specimen subject to tension-compression. There are no ratchet marks, and in the vicinity of the fracture zone there are several progression marks visible. The macro-crack plane is perpendicular to the specimen axis. On the fracture surface of specimens subject to lower loads, there are many river marks visible. Their endings indicate the fracture propagated in many directions. The macro-crack plane is located at an angle of $45^{\circ}$ in relation to the specimen axis. For $\lambda=0.5$, the fracture surface of the specimen subject to the highest loads is characterised by and extremely large fracture zone meaning that the material was under significant stress. The surface of the fatigue zone is irregular and the crack propagated from many origins and on various planes. In the case of a specimen subject to load of the lowest value, the fracture zone is smaller and fatigue zone as well as the macro-crack also indicate that the crack propagated on many planes.

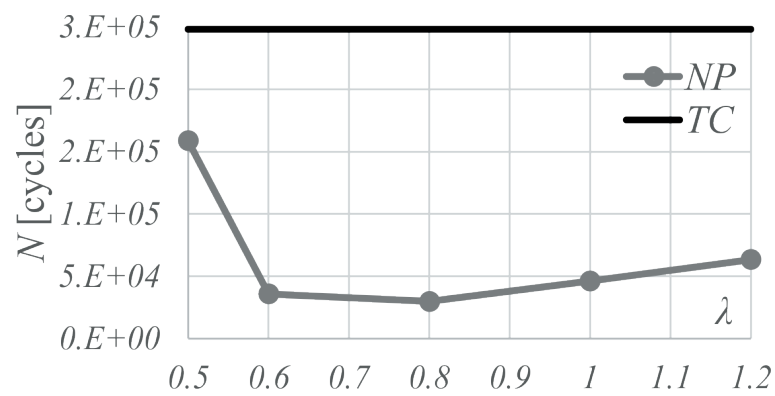

Fig. 10. Dependency of fatigue life on $\lambda$ for $X 2 \mathrm{CrNiMo17-12-2}$ steel, at the level of $\sigma_{e q}=310 \mathrm{MPa}$

The predominance of Case A crack growth is visible. The macro-crack of the specimen subject to a non-proportional load of coefficient $\lambda=0.7$, of the highest value is perpendicular to the specimen axis.

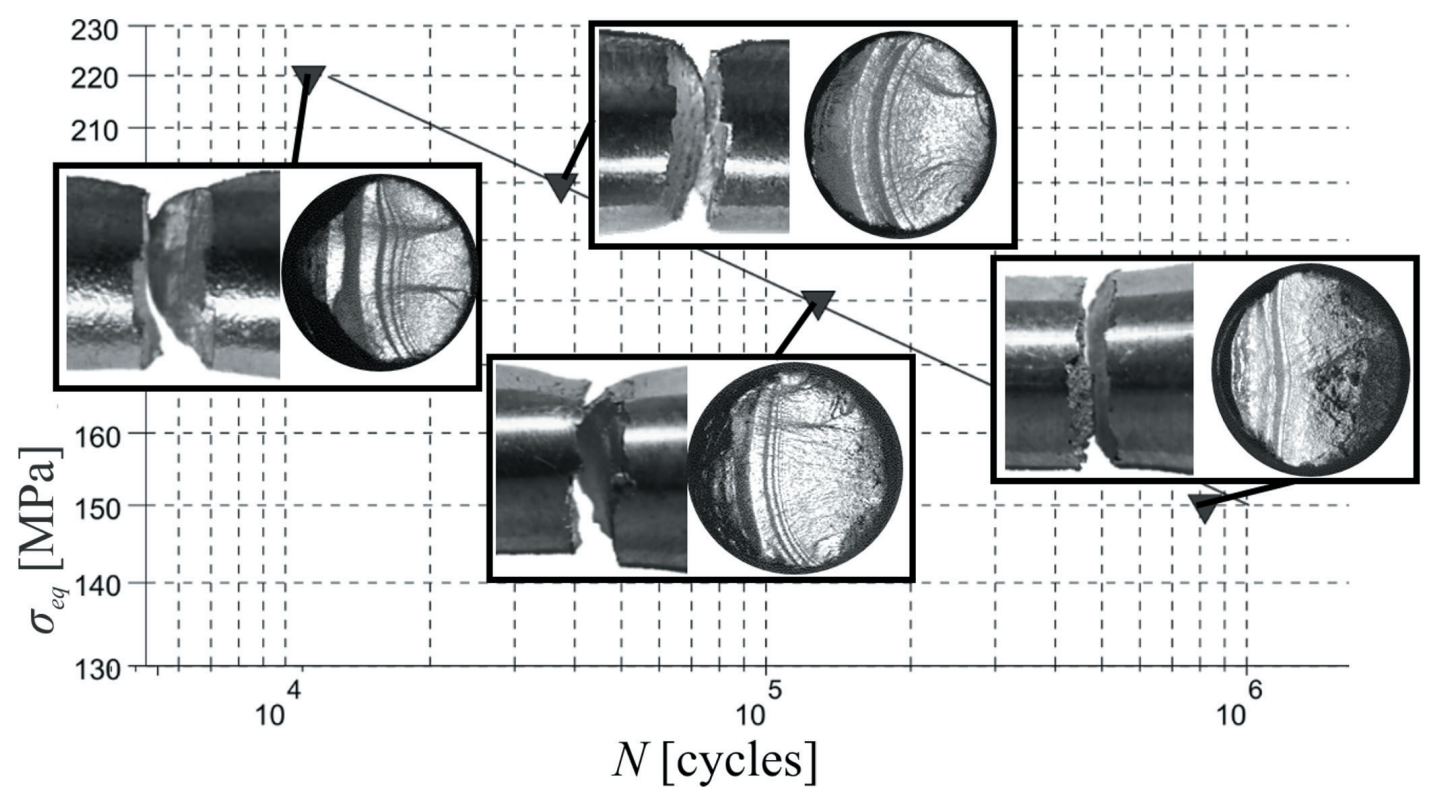

Fig. 11. Fractography of CU-ETP for tension-compression 


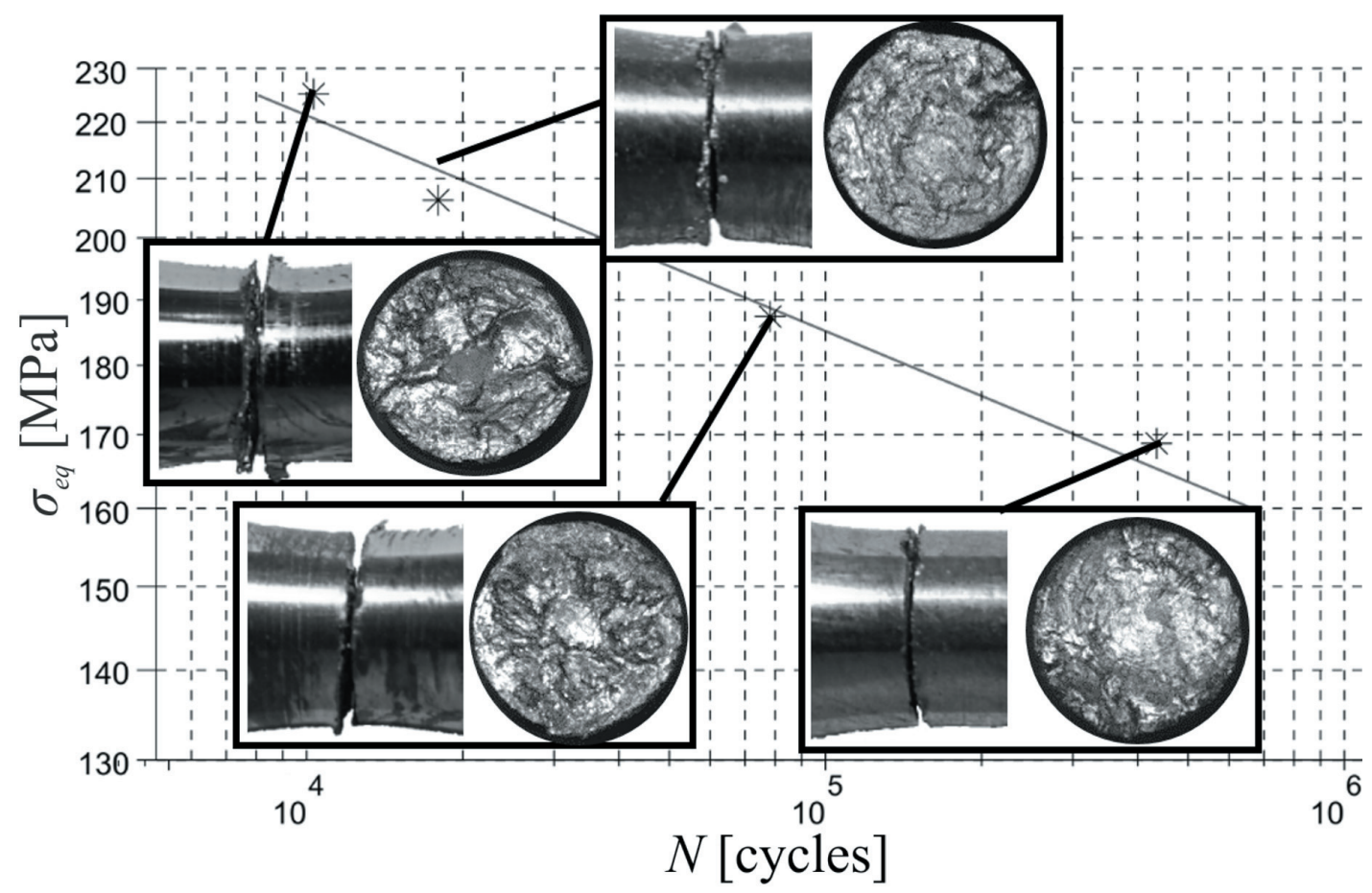

Fig. 12. Fractography of CU-ETP for torsion

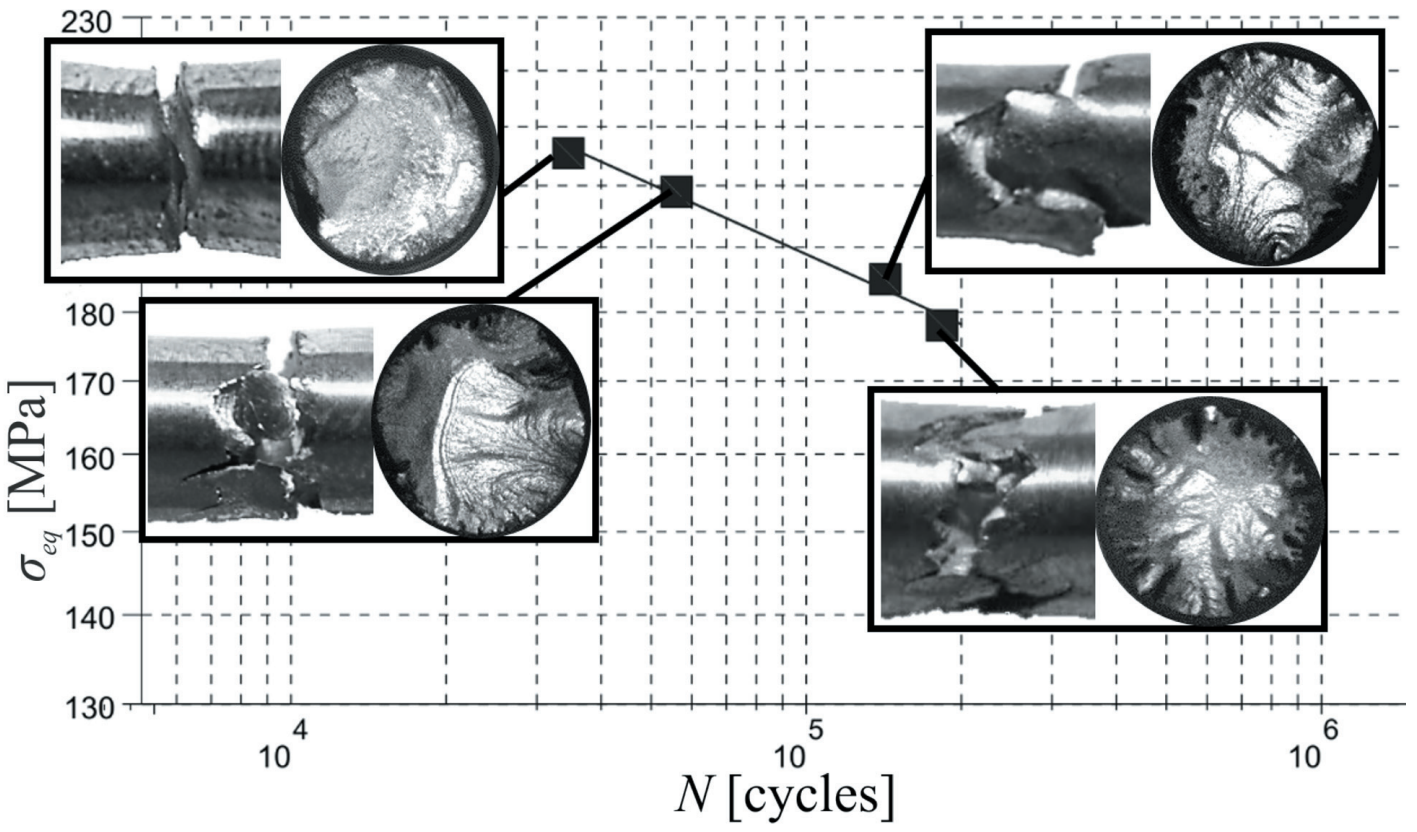

Fig. 13. Fractography of Cu-ETP for proportional load ( $\lambda=0.5$ )

The predominance of Case A crack growth is even higher and the fracture surface bears friction marks. The macro-crack and fracture surface of the specimen subject to loads of lower value indicate cracks in many origins and crack development on a greater number of planes.

To summarize, the characteristic feature of fracture surfaces of copper specimens subject to nonproportional load is the crack growth on many planes. 


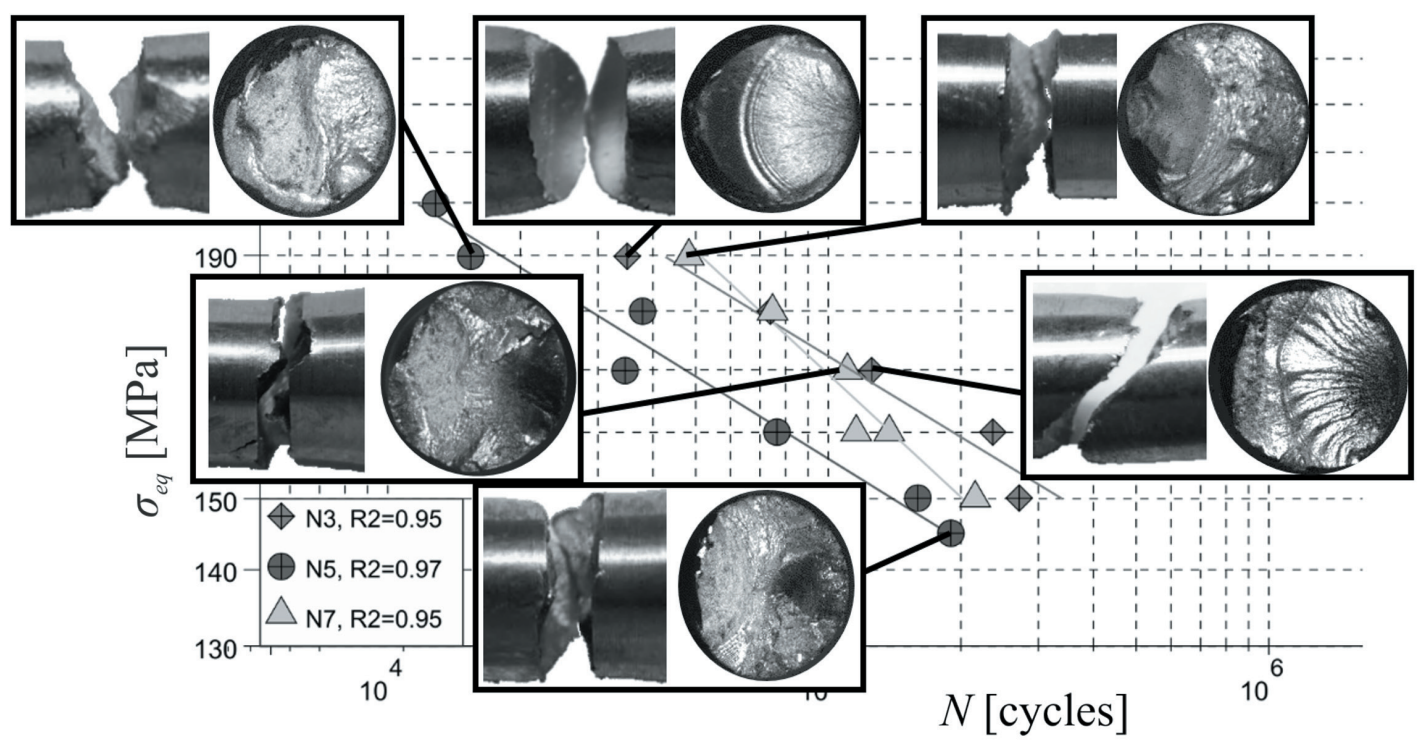

Fig. 14. Fractography of Cu-ETP for non-proportional loads ( $\lambda=0.3,0.5$ and 0.7 )

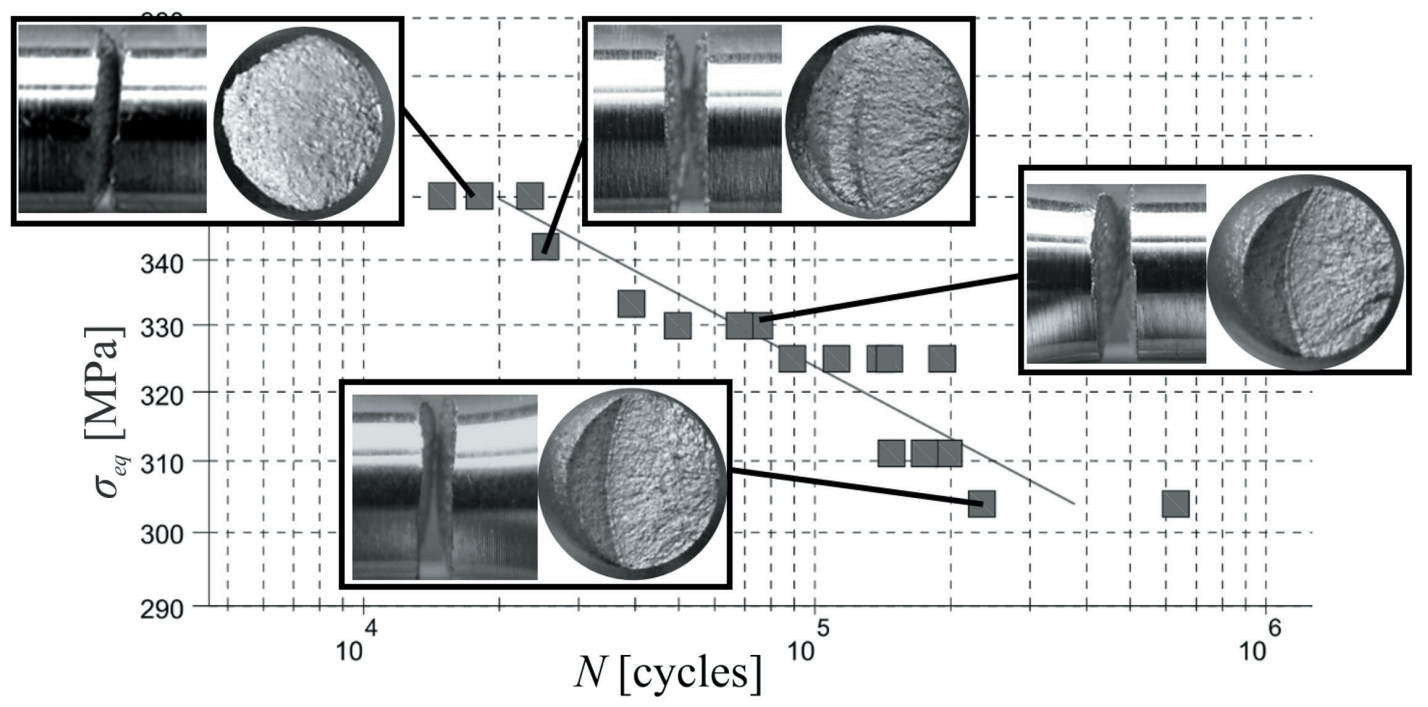

Fig. 15. Fractography of X2CrNiMo17-12-2 for tension-compression

Fig. 15 presents fracture surfaces morphology and cracks of specimens made of steel X2CrNiMo17-12-2, subject to tension-compression. The tensile mechanism causing the Case A and B crack growth can be observed. The fracture is perpendicular to the load direction. In the fatigue zone, there are no progression marks or ratchet marks. The crack initiation was of a single origin. The fracture zone decreases along with the load reduction.

Fig. 16 shows fracture surfaces morphology and specimen cracking of $\mathrm{X} 2 \mathrm{CrNiMo17-12-2,} \mathrm{which} \mathrm{were}$ subject to fully reversed torsion. In cases with a high load level, the crack direction is compliant with the direction of maximum shear stress. There is a Case A crack growth. The fracture surface is featureless due to friction. The reduction of load level caused the change of macro-crack direction by $45^{\circ}$. For medium load levels, one can observe that the crack propagated on two planes, whilst for the lower load level only on a single plane.

Fracture surfaces and cracks of $\mathrm{X} 2 \mathrm{CrNiMo17-12-2}$ specimens subject to proportional loads of coefficient values $\lambda=0.5$ and 0.8 are presented in Fig. 17. In the case of $\lambda=0.5$, cracks propagated at 


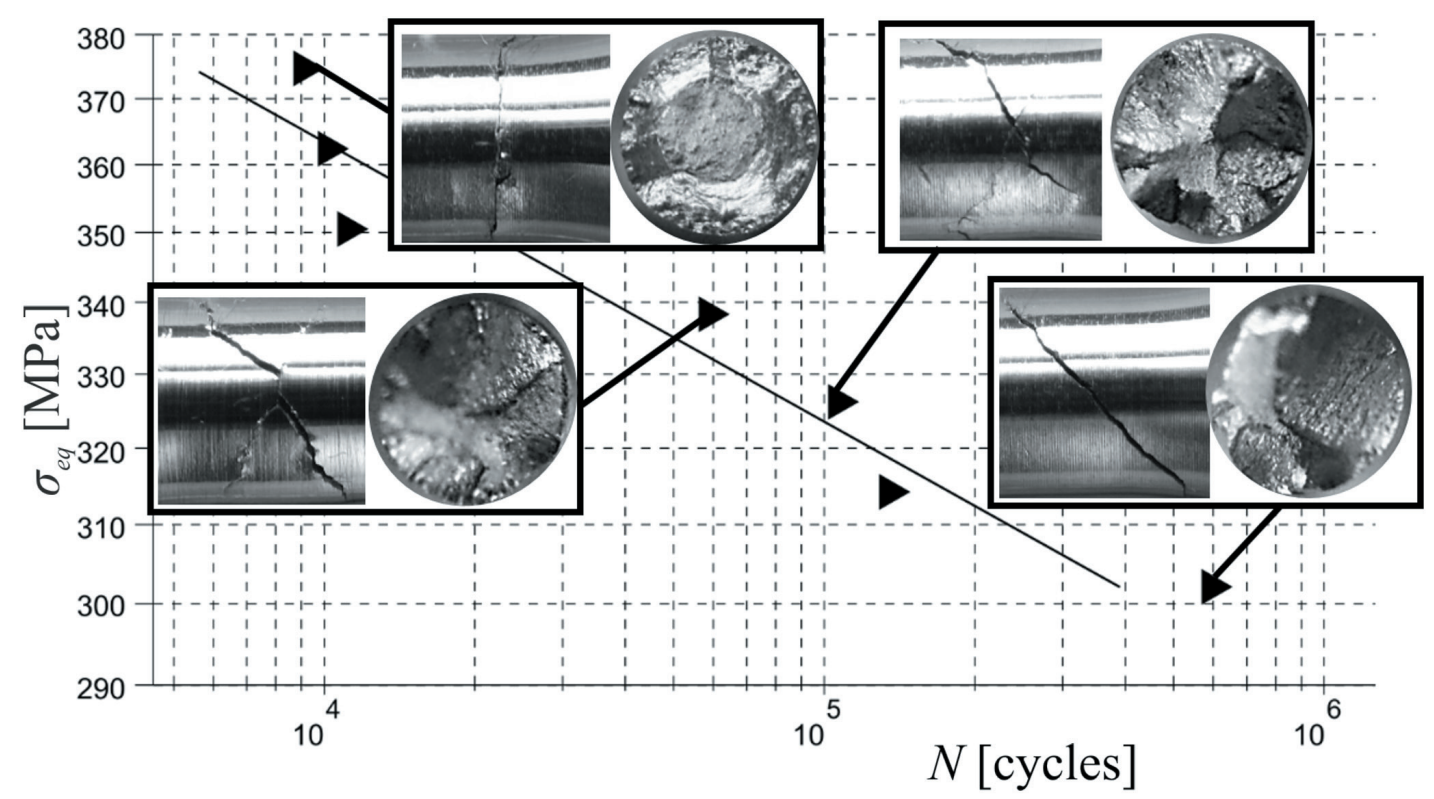

Fig. 16. Fractography of X2CrNiMo17-12-2 for torsion

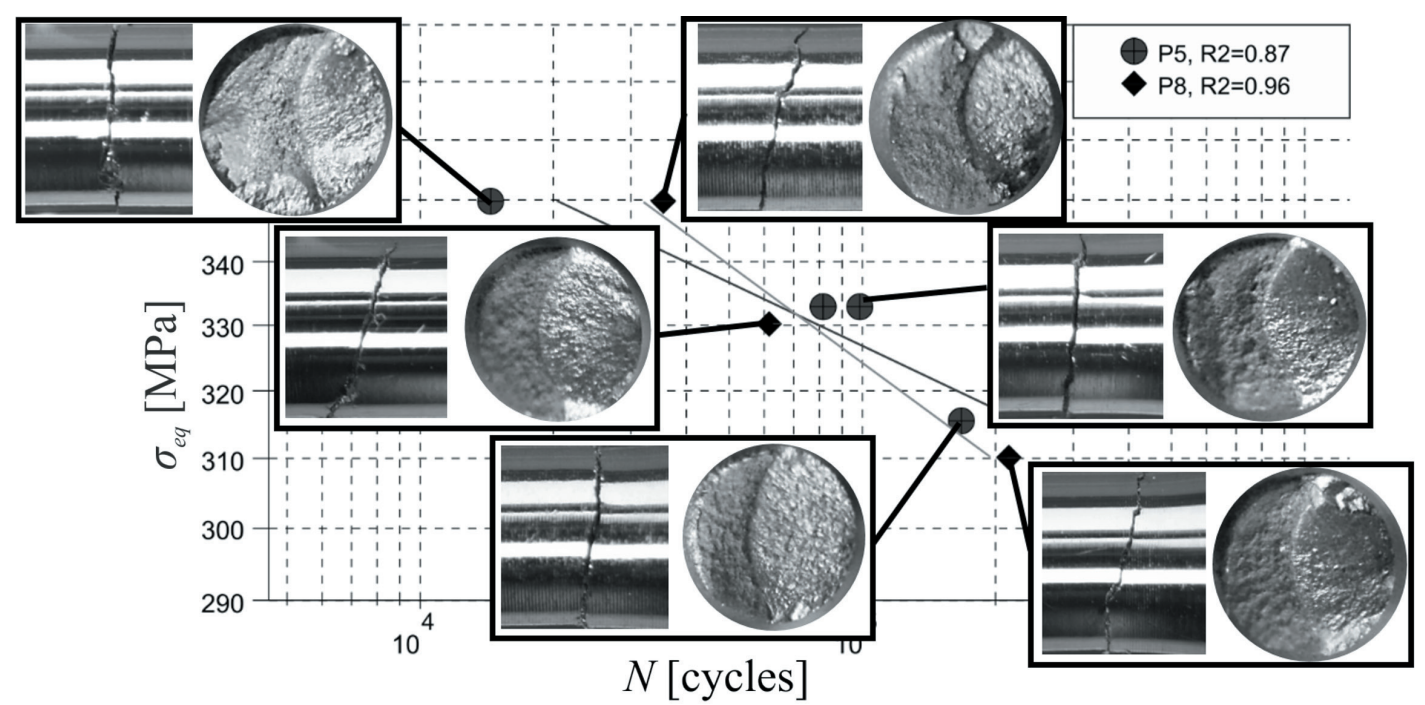

Fig. 17. Fractography of X2CrNiMo17-12-2 for proportional load $(\lambda=0.5,0.8)$

the angle of $7^{\circ}$, and for $\lambda=0.8$ at the angle of $15^{\circ}$. The difference is $8^{\circ}$, and it is identical with the value of change of angle of principal axes between these load cases. Fracture surfaces are similar to fracture surface for tension-compression with the difference that the crack propagated more inward with regards to the material (Case B), rather than along the crack length.

Fig. 18 shows fracture faces morphology and cracks of X2CrNiMo17-12-2 steel specimens subject to non-proportional loads of coefficient values $\lambda=0.5$ and 0.8 . In cases of $\lambda=0.5$, the crack propagated along perpendicular direction to the specimen axis and more inwards with regard to the material (Case B) than for $\lambda=0.5$ (more torsion), where it propagated more along the direction of the crack length (Case A) and at an angle of $30^{\circ}$.

Load non-proportionality resulted in the crack surface and its edge being highly irregular, indicating that the crack propagated on various planes. Similar to the case of $\mathrm{Cu}-\mathrm{ETP}$, the characteristic feature of fracture surfaces of specimens subject to nonproportional load is the crack propagation on many planes. 
Table 5. Summary of fracture features for CU-ETP copper

\begin{tabular}{|c|c|c|c|c|c|c|c|}
\hline & \multirow{2}{*}{$\begin{array}{c}\text { Tension } \\
\lambda=0\end{array}$} & \multirow{2}{*}{$\begin{array}{l}\text { Torsion } \\
\lambda=\infty\end{array}$} & \multirow{2}{*}{$\begin{array}{c}\text { Proportional } \\
\lambda=0.5\end{array}$} & \multicolumn{3}{|c|}{ Non-proportional } \\
\hline & & & & & $\lambda=0.3$ & $\lambda=0.5$ & $\lambda=0.7$ \\
\hline \multirow{5}{*}{ 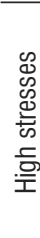 } & Macro fracture plane direction & $\perp \sigma_{1 \max }$ & $\| \tau_{\alpha \max }$ & $\perp \sigma_{1 \max }$ & $\perp \sigma_{1 \max }$ & $\perp \sigma_{1 \max }$ & $\perp \sigma_{1 \max }$ \\
\hline & Crack growth case & $A \approx B$ & A & $A \approx B$ & $A \approx B$ & $A \approx B$ & $A>>B$ \\
\hline & Number of origins & multiple & multiple & multiple & single & single & single \\
\hline & Ratchets marks presence & yes & no & tapered & no & no & yes \\
\hline & $\begin{array}{l}\text { Progression marks / } \\
\text { river marks presence }\end{array}$ & $\begin{array}{c}\text { yes / } \\
\text { no }\end{array}$ & $\begin{array}{c}\text { no } / \\
\text { no }\end{array}$ & $\begin{array}{c}\text { no } / \\
\text { no }\end{array}$ & $\begin{array}{c}\text { yes / } \\
\text { no }\end{array}$ & $\begin{array}{c}\text { no / } \\
\text { no }\end{array}$ & $\begin{array}{c}\text { no } / \\
\text { no }\end{array}$ \\
\hline \multirow{5}{*}{ 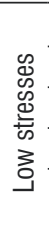 } & Macro fracture plane direction & $\perp \sigma_{1 \max }$ & $\| \tau_{\alpha \max }$ & $\perp \sigma_{1 \max }$ & $\| \tau_{\alpha \max }$ & $\perp \sigma_{1 \max }$ & $\perp \sigma_{1 \max }$ \\
\hline & Crack growth case & $A \approx B$ & A & difficult to identify & $A \approx B$ & $A>B$ & $A>>B$ \\
\hline & Number of origins & single & multiple & multiple & single & single & single \\
\hline & Ratchets marks presence & no & no & tapered & tapered & no & no \\
\hline & $\begin{array}{l}\text { Progression marks / } \\
\text { river marks presence }\end{array}$ & $\begin{array}{c}\text { yes / } \\
\text { no }\end{array}$ & $\begin{array}{c}\text { no / } \\
\text { no }\end{array}$ & $\begin{array}{c}\text { no / } \\
\text { no }\end{array}$ & $\begin{array}{l}\text { no / } \\
\text { yes }\end{array}$ & $\begin{array}{c}\text { no } / \\
\text { no }\end{array}$ & $\begin{array}{c}\text { no } / \\
\text { no }\end{array}$ \\
\hline
\end{tabular}

Table 6. Summary of fracture features for X2CrNiMo17-12-2 steel

\begin{tabular}{|c|c|c|c|c|c|c|c|}
\hline & & \multirow{2}{*}{$\begin{array}{c}\text { Tension } \\
\lambda=0 \\
\end{array}$} & \multirow{2}{*}{$\begin{array}{l}\text { Torsion } \\
\lambda=\infty\end{array}$} & \multicolumn{2}{|c|}{ Proportional } & \multicolumn{2}{|c|}{ Non-proportional } \\
\hline & & & & $\lambda=0.5$ & $\lambda=0.8$ & $\lambda=0.5$ & $\lambda=0.8$ \\
\hline \multirow{6}{*}{ 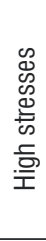 } & Macro-fracture plane direction & $\perp \sigma_{1 \max }$ & $\| \tau_{\alpha \max }$ & difficult to identify & difficult to identify & $\perp \sigma_{M \max }$ & $\perp \sigma_{M \max }$ \\
\hline & Crack growth case & $A \approx B$ & $\mathrm{~A}$ & $B \approx A$ & $A \approx B$ & $A \approx B$ & $A>>B$ \\
\hline & Number of origins & single & multiple & single & multiple & single & single \\
\hline & Ratchets marks presence & no & no & no & no & no & no \\
\hline & Progression marks / & no / & no / & no / & no / & no / & no / \\
\hline & river marks presence & no & no & no & no & no & no \\
\hline \multirow{5}{*}{ 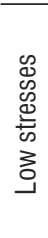 } & Macro-fracture plane direction & $\perp \sigma_{1 \max }$ & $\perp \sigma_{1 / 2 \max }$ & difficult to identify & difficult to identify & $\perp \sigma_{M \max }$ & $\perp \sigma_{M \text { max }}$ \\
\hline & Crack growth case & $A \approx B$ & A & $B \approx A$ & $A \approx B$ & $A \approx B$ & $A>B$ \\
\hline & Number of origins & single & multiple & single & single & single & single \\
\hline & Ratchets marks presence & no & no & no & no & no & no \\
\hline & $\begin{array}{l}\text { Progression marks / } \\
\text { river marks presence }\end{array}$ & $\begin{array}{c}\text { no / } \\
\text { no }\end{array}$ & $\begin{array}{c}\text { no } / \\
\text { no }\end{array}$ & $\begin{array}{c}\text { no / } \\
\text { no }\end{array}$ & $\begin{array}{c}\text { no } / \\
\text { no }\end{array}$ & no / & no / \\
\hline
\end{tabular}

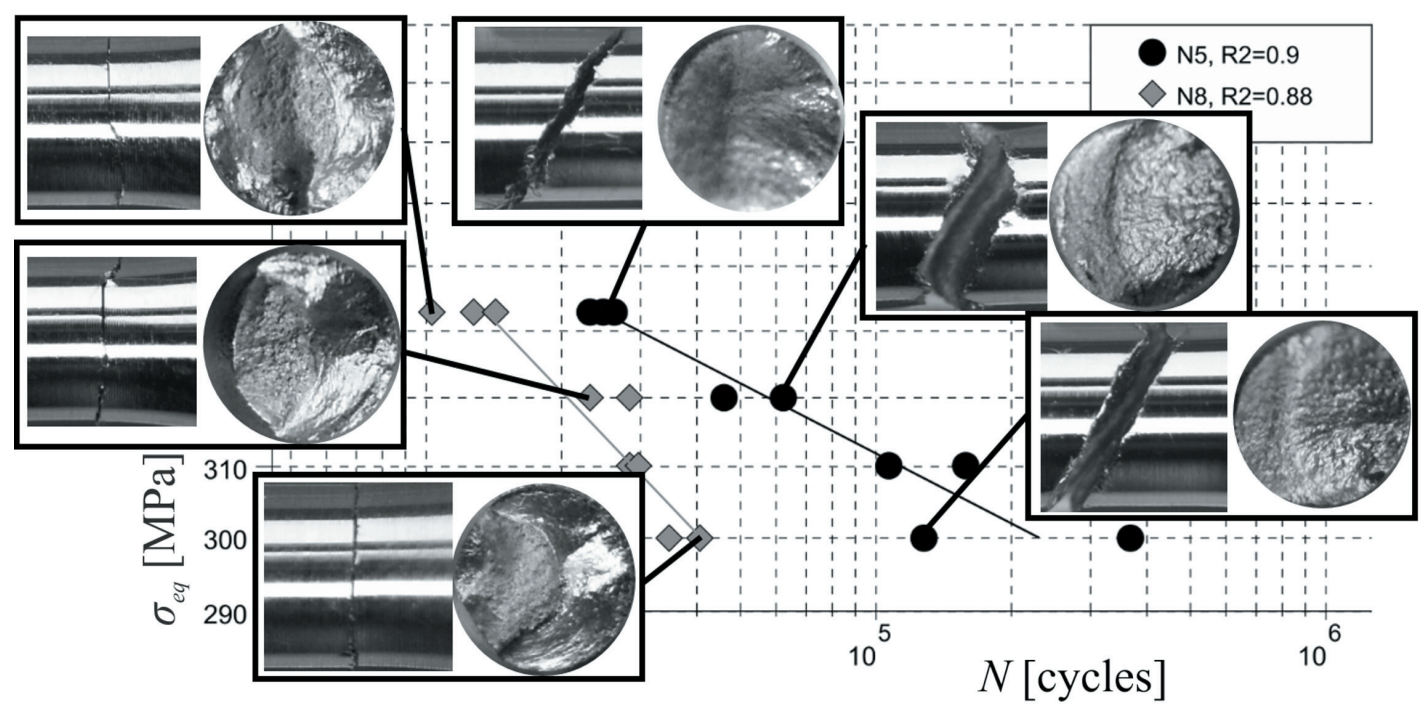

Fig. 18. Fractography of X2CrNiMo17-12-2 for non-proportional loads $(\lambda=0.5,0.8)$ 
The summaries of fracture features are presented in Tables 5 and 6.

Fracture surfaces of specimens subjected to nonproportional loads are different than for specimens subjected to proportional loads. Generally, in cases of non-proportional loads, cracks grow on many planes, thus the fracture surfaces are irregular.

Similarly to fatigue lives, the features of fracture surfaces strongly depend on the $\lambda$ ratio. For high values of $\lambda$, more Case A than B crack growth mode can be observed, while in the case of proportional loads there was a similar amount of Case A and B crack growth mode. The influence of the most damaging value of $\lambda$ ratio is also visible. Fracture surfaces are most irregular for the most non-proportional load, and cracks nucleated from many origins and propagated on many planes. The fracture zones are large, which indicates a high stress level.

\section{SUMMARY AND CONCLUSIONS}

A detailed study of the impact of shear to normal stress amplitudes, $\lambda=\tau_{a} / \sigma_{a}$, on the fatigue life and fracture surface morphology of materials sensitive to non-proportional loadings has been conducted.

Both tested materials showed high sensitivity to non-proportionality of load. In the case of Cu-ETP copper application of fatigue criterion in a manner stressing the impact of non-proportional loads, it resulted in over-estimation of fatigue strength by about $22 \%$ and fatigue life by about $450 \%$ in extreme cases. ForX2CrNiMo17-12-2 steel, it was ca. 10\% and ca. $650 \%$, respectively.

For both materials the value of shear to normal stress ratio $\lambda$ had significant impact on fatigue life. Values of coefficient $\lambda$ close to relation $\tau_{-1} / \sigma_{-1}$ turned out to be the most damaging both for copper and for austenitic steel.

A similar dependence on the value of the $\lambda$ ratio was observed in case of fracture surfaces. It had an impact on their morphology and the orientation of the macro-fracture plane.

It is worth emphasizing that for both materials the critical value of $\lambda$ was different. This allows for the creation of the hypothesis that for materials subject to out-of-phase loads the most damaging are loads with components shifted in phase by $90^{\circ}$ and of shear-tonormal stress ratio equal to $\tau_{-1} / \sigma_{-1}$.

Therefore, it seems that for estimation of fatigue strength and fatigue life in the conditions of nonproportional loads, the relation of fatigue limits $\tau_{-1} / \sigma_{-1}$ is of very high importance.
The microscopic models of non-proportional fatigue failure mechanisms are highly general, regardless of the material (steel [17], aluminium alloy [18], non-ferrous metals, [19] to [21], general (hypothetic) [22]). At this stage of research, it is difficult to directly show their relationship with macroscopic phenomena presented in the article.

\section{ACKNOWLEDGEMENT}

The project has been financed by the Polish National Science Centre. Project number: N N501 120940.

\section{REFERENCES}

[1] McDiarmid, D.L. (1986). Fatigue under out-ofphase bending and torsion. Fatigue \& Fracture of Engineering Materials \& Structures, vol. 9, no. 6, p. 457-475, DOI:10.1111/j.1460-2695.1987.tb00471.x.

[2] Ellyin, F., Golos, K., Xia, Z. (1991). In-phase and outof-phase multiaxial fatigue. Journal of Engineering Materials and Technology-Transactions of the ASME, vol. 113, no. 1, p. 112-118, DOI:10.1115/1.2903365.

[3] Socie, D.F., Marquis, G.B. (1999). Multiaxial Fatigue. SAE International, Washington D.C.

[4] Fatemi, A., Shamsaei, N. (2011). Multiaxial fatigue: An overview and some approximation models for life estimation. International Journal of Fatigue, vol. 33, no. 8, p. 948-958, DOI:10.1016/j.ijfatigue.2011.01.003.

[5] Noban, M., Jahed, H., Ibrahim, E., Ince, A. (2012). Load path sensitivity and fatigue life estimation of $30 \mathrm{CrNiMo8HH}$. International Journal of Fatigue, vol. 37, no. p. 123-133, DOI:10.1016/j. ijfatigue.2011.10.009.

[6] Zenner, H., Simburger, A., Liu, J. (2000). On the fatigue limit of ductile metals under complex multiaxial loading. International Journal of Fatigue, vol. 22, no. 2, p. 137-145, DOI:10.1016/S0142-1123(99)00107-3.

[7] Verreman, Y., Guo, H. (2007). High-cycle fatigue mechanisms in 1045 steel under non-proportional axialtorsional loading. Fracture of Engineering Materials \& Structures, vol. 30, no. 10, p. 932-946, DOI:10.1111/ j.1460-2695.2007.01164.x.

[8] Papadopoulos, I.V. (2001). Long life fatigue under multiaxial loading. International Journal of Fatigue, vol. 23, no. 10, p. 839-849, DOI:10.1016/S01421123(01)00059-7.

[9] Karolczuk, A. (2006). Plastic strains and the macroscopic critical plane orientations under combined bending and torsion with constant and variable amplitudes. Engineering Fracture Mechanics, vol. 73 , no. 12 , p. 1629-1652, DOI:10.1016/j. engfracmech.2006.02.005.

[10] Marciniak, Z., Rozumek, D., Macha, E. (2008). Fatigue lives of 18G2A and 10HNAP steels under variable amplitude and random non-proportional bending with torsion loading. International Journal 
of Fatigue, vol. 30, no. 5, p. 800-813, DOI:10.1016/j. ijfatigue.2007.07.001.

[11] Banvillet, A., Łagoda, T., Macha, E., Niesłony, A, Palin-Luc, T., Vittori, J.-F. (2004). Fatigue life under non-gaussian random loading from various models. International Journal of Fatigue, vol. 26, no. 4, p. 349363, DOI:10.1016/j.ijfatigue.2003.08.017.

[12] Roy, M., Nadot, Y., Maijer, D.M., Benoit, G. (2012). Multiaxial fatigue behaviour of A356-T6. Fatigue \& Fracture of Engineering Materials \& Structures, vol. 35 , no. 12 , p. $1148-1159$, DOI:10.1111/j.14602695.2012.01702.x.

[13] Zhang, J., Shi, X., Bao, R., Fei, B. (2011). Tensiontorsion high-cycle fatigue failure analysis of 2A12-T4 aluminum alloy with different stress ratios. International Journal of Fatigue, vol. 33, no. 8, p. 1066-1074, DOI:10.1016/j.ijfatigue.2010.12.007.

[14] Borodii, M.V., Shukaev, S.M. (2007). Additional cyclic strain hardening and its relation to material structure, mechanical characteristics, and lifetime. International Journal of Fatigue, vol. 29, no. 6, p. 1184-1191, DOI:10.1016/j.ijfatigue.2006.06.014.

[15] Papadopoulos, I.V., Davoli, P., Gorla, C., Filippini, M., Bernasconi, A. (1997). A comparative study of multiaxial high-cycle fatigue criteria for metals. International Journal of Fatigue, vol. 19, no. 3, p. 219235, DOI:10.1016/S0142-1123(96)00064-3.

[16] Lee, Y.L., Pan, J., Hathaway, R., Barkey, M. (2004). Fatigue Testing and Analysis. Butterworth-Heinemann, Oxford.
[17] Kida, S., Itoh, T., Sakane, M., Ohnami, M., Socie, D. F. (1997). Dislocation Structure and Non-Proportional Hardening of Type 304 Stainless Steel. Fatigue \& Fracture of Engineering Materials \& Structures, vol. 20, no. 10, p. 1375-1386, DOI:10.1111/j.1460-2695.1997. tb01496.x.

[18] Zhang, J., Shi, X., Fei, B. (2012). High cycle fatigue and fracture mode analysis of 2A12-T4 aluminum alloy under out-of-phase axial-torsion constant amplitude loading. International Journal of Fatigue, vol. 38, p. 144-154, DOI:10.1016/j.ijfatigue.2011.12.017.

[19] Bentachfine, S., Pluvinage, G. (1996). Biaxial low cycle fatigue under non-proportional loading of a magnesiumlithium alloy. Engineering Fracture Mechanics, vol. 54, no. 4, p. 513-522, DOI:10.1016/0013-7944(95)002235.

[20] Zhang, J., Jiang, Y. (2005). An experimental investigation on cyclic plastic deformation and substructures of polycrystalline copper. International Journal of Plasticity, vol. 21, no. 11, p. 2191-2211, DOI:10.1016/j.ijplas.2005.02.004.

[21] Ding, X., He, G., Chen, C. (2010). Study on the dislocation sub-structures of $\mathrm{Al}-\mathrm{Mg}-\mathrm{Si}$ alloys fatigued under non-proportional loadings. Journal of Materials Science, vol. 45, no. 15 , p. 4046-4053, DOI:10.1007/ s10853-010-4487-3.

[22] Colak, U.O. (2004). A viscoplasticity theory applied to proportional and non-proportional cyclic loading at small strains. International Journal of Plasticity, vol. 20, no. 8-9, p. 1387-1401, DOI:10.1016/j. ijplas.2003.07.002. 